\title{
Soil solution phosphorus turnover: derivation, interpretation, and insights from a global compilation of isotope exchange kinetic studies
}

\author{
Julian Helfenstein $^{1}$, Jannes Jegminat ${ }^{2}$, Timothy I. McLaren ${ }^{1}$, and Emmanuel Frossard ${ }^{1}$ \\ ${ }^{1}$ Institute of Agricultural Sciences, ETH Zurich, Lindau, 8315, Switzerland \\ ${ }^{2}$ Institute of Neuroinformatics, University of Zurich and ETH Zurich, Zurich, 8057, Switzerland
}

Correspondence: Julian Helfenstein (julian.helfenstein@usys.ethz.ch)

Received: 17 July 2017 - Discussion started: 10 August 2017

Revised: 22 November 2017 - Accepted: 23 November 2017 - Published: 8 January 2018

\begin{abstract}
The exchange rate of inorganic phosphorus (P) between the soil solution and solid phase, also known as soil solution $\mathrm{P}$ turnover, is essential for describing the kinetics of bioavailable $\mathrm{P}$. While soil solution $\mathrm{P}$ turnover $\left(K_{\mathrm{m}}\right)$ can be determined by tracing radioisotopes in a soil-solution system, few studies have done so. We believe that this is due to a lack of understanding on how to derive $K_{\mathrm{m}}$ from isotopic exchange kinetic (IEK) experiments, a common form of radioisotope dilution study. Here, we provide a derivation of calculating $K_{\mathrm{m}}$ using parameters obtained from IEK experiments. We then calculated $K_{\mathrm{m}}$ for 217 soils from published IEK experiments in terrestrial ecosystems, and also that of 18 long-term $\mathrm{P}$ fertilizer field experiments. Analysis of the global compilation data set revealed a negative relationship between concentrations of soil solution P and $K_{\mathrm{m}}$. Furthermore, $K_{\mathrm{m}}$ buffered isotopically exchangeable P in soils with low concentrations of soil solution P. This finding was supported by an analysis of long-term $P$ fertilizer field experiments, which revealed a negative relationship between $K_{\mathrm{m}}$ and phosphate-buffering capacity. Our study highlights the importance of calculating $K_{\mathrm{m}}$ for understanding the kinetics of $\mathrm{P}$ between the soil solid and solution phases where it is bioavailable. We argue that our derivation can also be used to calculate soil solution turnover of other environmentally relevant and strongly sorbing elements that can be traced with radioisotopes, such as zinc, cadmium, nickel, arsenic, and uranium.
\end{abstract}

\section{Introduction}

As an essential but often limiting nutrient, phosphorus $(\mathrm{P})$ plays a central role in food production, and more efficient $\mathrm{P}$ management is key to improve food security (Tilman et al., 2002; Syers et al., 2008). Phosphorus limitation in agroecosystems is usually overcome by applying $\mathrm{P}$ fertilizers to the soil surface. However, excessive applications of $\mathrm{P}$ fertilizer to soil can cause ecological, societal, and economic problems. First, $P$ fertilizer is largely derived from rock phosphate, which is a non-renewable resource and major deposits are located in only a few countries (Elser and Bennett, 2011; Obersteiner et al., 2013). Second, applications of P fertilizers to soils with a high $\mathrm{P}$ sorption capacity can be inefficient because P largely accumulates in the soil in sparingly soluble forms (Roy et al., 2016). Third, leaching or runoff of $P$ fertilizer from agricultural land to aquatic and marine ecosystems contributes to fish die-off and declining water quality (Carpenter et al., 1998). To improve food security while reducing ecosystem pollution, it is essential that we improve our understanding of soil $\mathrm{P}$ dynamics, particularly the mechanisms controlling P movement between the soil solid phase and the soil solution where it is bioavailable.

Plants take up $\mathrm{P}$ from the soil solution as ionic orthophosphate $\left(\mathrm{H}_{2} \mathrm{PO}_{4}^{-}\right.$or $\left.\mathrm{HPO}_{4}^{2-}\right)$ via roots or mycorrhizal hyphae (Pierzynski and McDowell, 2005). The soil solution typically contains low concentrations of P (Achat et al., 2016), but the soil solution can be replenished with $\mathrm{P}$ from the soil solid phase, which can provide additional $\mathrm{P}$ for uptake by plants (Pierzynski and McDowell, 2005). Therefore, P exchange kinetics, or the rate at which the soil solution is replenished by 
P from the soil solid phase, have important implications for the $P$ requirements of living organisms (Menezes-Blackburn et al., 2016; Fardeau et al., 1991). In this study, we investigate a potential link between two different concepts, phosphorusbuffering capacity and soil solution $\mathrm{P}$ turnover, by analyzing a data set of global soils and $\mathrm{P}$ fertilizer experiments.

Phosphorus-buffering capacity (PBC) is defined as the ability of soil to moderate changes in the concentration of soil solution P (Pypers et al., 2006; Olsen and Khasawneh, 1980; Beckett and White, 1964). Historically, PBC has been calculated using Eq. (1).

$\mathrm{PBC}=\frac{\Delta \text { conc. of } \mathrm{P} \text { in soil solution }}{\Delta \text { conc. of } \mathrm{P} \text { in the soil }}$

The traditional approach of determining PBC in soil is to add various amounts of $\mathrm{P}$ to a soil suspension, equilibrate, and then measure the slope between adsorbed $\mathrm{P}$ and $\mathrm{P}$ in soil solution (Olsen and Khasawneh, 1980). Alternatively, PBC can be measured by analyzing the change in soil solution $P$ concentration with regard to $\mathrm{P}$ budget in field $\mathrm{P}$ fertilization experiments (Morel et al., 2000). These approaches have revealed that $\mathrm{PBC}$ is influenced by ambient temperature, soil solution $\mathrm{pH}$, and concentrations of $\mathrm{P}$ in the soil solution, and is highly variable among soil types (Barrow, 1983). One of the most important factors among soil types is the specific surface area of $\mathrm{Fe} / \mathrm{Al}$ oxides and clay minerals, which are important sites of $\mathrm{P}$ sorption (Gérard, 2016). Whilst the aforementioned approaches are a useful and cost effective way to study soil $\mathrm{P}$ dynamics (Bolland and Allen, 2003; Burkitt et al., 2002; Barrow and Debnath, 2014), they are not able to directly determine the turnover of $\mathrm{P}$ in the solution.

Soil solution $\mathrm{P}$ turnover $\left(K_{\mathrm{m}}\right)$ is the mean rate of exchange between phosphate ions in solution and inorganic phosphate in soil and can be calculated from parameters determined in an isotopic exchange kinetic (IEK) experiment (Fardeau, 1996). Isotopic exchange kinetic experiments involve the use of $\mathrm{P}$ radioisotopes $\left({ }^{32} \mathrm{P}\right.$ or $\left.{ }^{33} \mathrm{P}\right)$ to directly measure the exchange of $\mathrm{P}$ between the soil solid and solution phases (Frossard et al., 2011). They are based on the assumption that during the short-term experiments, usually lasting $100 \mathrm{~min}$, there is only physicochemical exchange but no biological exchange (Oehl et al., 2001). Measurements of isotopically exchangeable $\mathrm{P}$ are a more accurate indicator of $\mathrm{P}$ bioavailability than conventional soil tests based on chemical extraction because the former involves a $\mathrm{P}$ radiotracer that can be directly measured and distinguished from all other $\mathrm{P}$ ions in the soil (Demaria et al., 2005; Hamon et al., 2002). Previous studies have shown that isotopically exchangeable $\mathrm{P}$ is the predominant source of $\mathrm{P}$ for most crops (Frossard et al., 1994; Morel and Plenchette, 1994). Though the IEK approach does not consider root-induced $\mathrm{pH}$ alterations or secretion of organic acids, increased $\mathrm{P}$ availability due to root exudates can be quantified by comparing isotopically exchangeable $\mathrm{P}$ with radioisotope uptake in plants (Hedley et al., 1982). Isotopic dilution in a soil solution system is characterized by two statistically fitted parameters, $m$ and $n$, which can be used to calculate $K_{\mathrm{m}}$ using Eq. (2) (Fardeau, 1985; Fardeau et al., 1991).

$K_{\mathrm{m}}=\frac{n}{m^{\frac{1}{n}}}$

The importance of parameters $m$ and $n$ as well as their relation to soil properties was recently investigated (Achat et al., 2016).

Despite several decades of using radioisotopes in $\mathrm{P}$ research and the potential relevance of soil solution $\mathrm{P}$ turnover to understanding agricultural and natural ecosystems, only six studies have published $K_{\mathrm{m}}$ values, and there has been no synthesis of these values (Frossard et al., 2011; Fardeau et al., 1991; Fardeau, 1985, 1993; Oberson et al., 1993; Xiong et al., 2002). We believe that this is because an intuitive derivation of $K_{\mathrm{m}}$ has never been published. Whilst information on soil solution $\mathrm{P}$ turnover remains limited, $K_{\mathrm{m}}$ values can easily be calculated using data from previously published IEK experiments.

The first aim of our study was to provide a clear and intuitive derivation of the $K_{\mathrm{m}}$ term. Our second aim was to calculate $K_{\mathrm{m}}$ values from previously published IEK studies, which resulted in a global data set of over 200 soils. We then tested specific hypotheses related to concentrations of soil solution $\mathrm{P}$ and isotopically exchangeable P. Our third aim was to understand the relationship between $\mathrm{PBC}$ and $K_{\mathrm{m}}$. This involved an additional data set based on long-term $\mathrm{P}$ fertilizer field experiments, which reported IEK results and the $\mathrm{P}$ fertilizer budgets. Lastly, we carried out a sensitivity analysis of $K_{\mathrm{m}}$ in order to assist in interpretation of future results.

Our first hypothesis was that turnover of soil solution $\mathrm{P}$ would differ based on soil group. More specifically, we hypothesized that soil groups known to have higher concentrations of sorption sites (such as Andosols and Ferralsols) would have faster turnover rates. Our second hypothesis was that soils with higher concentrations of soil solution $\mathrm{P}\left(P_{\mathrm{w}}\right)$ would have lower values of $K_{\mathrm{m}}$ compared to soil with lower concentrations of soil solution $\mathrm{P}$. This is because a high concentration of sorption sites leads to fast adsorption and consequently low concentration of $\mathrm{P}$ in the solution. Lastly, we hypothesized that the dependence of isotopically exchangeable $\mathrm{P}$ on $P_{\mathrm{w}}$ and $K_{\mathrm{m}}$ evolves with time.

\section{Materials and methods}

\subsection{Derivation of $K_{\mathrm{m}}$}

A given volume of soil can be described as containing inorganic $\mathrm{P}$ in one of two states: the soil phase or the soil solution phase. In any given time interval, physicochemical reactions transfer a fraction of $\mathrm{P}$ from the soil solution phase into the solid phase. The rate constant of this reaction is solution $\mathrm{P}$ turnover $K_{\mathrm{m}}\left(\mathrm{min}^{-1}\right)$. Thus, $K_{\mathrm{m}}$ plays a critical role in deter- 
mining the time and amount of $\mathrm{P}$ that is potentially available to plants. At low values of $K_{\mathrm{m}}$, there is little exchange.

At equilibrium, an underlying assumption of an IEK experiment, the net flux between the phases is zero because of the balancing effect of the inverse flux, i.e., the flux from the soil phase to the solution phase through desorption and dissolution. In other words, the inverse flux prevents us from measuring $K_{\mathrm{m}}$ directly by fitting the temporal loss of $\mathrm{P}$ in soil solution. If radioisotopes (for $\mathrm{P}$, either ${ }^{32} \mathrm{P}$ or ${ }^{33} \mathrm{P}$ ) are injected into the soil solution, it becomes possible to experimentally eliminate the inverse flux. Shortly after the injection, the radioisotope is not present in the solid phase and, consequently, there is no inverse flux. Equation (3) has been found to describe the resulting decline of radioisotope in solution (Fardeau et al., 1991; Frossard et al., 2011).

$\frac{r_{(t)}}{R}=m\left(t+m^{\frac{1}{n}}\right)^{-n}+\frac{r_{(\infty)}}{R}$,

where $r_{(t)}$ is the radioactivity (Bq) measured at time $t$ (min), $R$ is the total amount of radioactivity added, and $m$ and $n$ are the model parameters that describe the rapid and slow physicochemical processes, respectively. Since $K_{\mathrm{m}}$ is equivalent to the decline rate of the radioisotope in the absence of an inverse flux, we analyze Eq. (3) right after the injection $(t=0)$ and derive Eq. (2) (for details on the derivation, please see Supplement).

$K_{\mathrm{m}}$ is thus calculated in three steps: first, $r_{(t)} / R$ is measured, then $n$ and $m$ are determined by nonlinear regression, and finally Eq. (2) is applied. A limitation of $K_{\mathrm{m}}$ is that it does not take into account an indefinite number of $\mathrm{P}$ species each with their own exchange rate (Andersson et al., 2016; Menezes-Blackburn et al., 2016; Gérard, 2016). Also, the IEK method as described above does not consider microbial uptake or mineralization of organic P (Oehl et al., 2001). Therefore, the variable $K_{\mathrm{m}}$ should be considered as the average $\mathrm{P}$ exchange rate of the soil solution with an indefinite number of solid inorganic $\mathrm{P}$ pools.

\subsection{Data set}

We carried out a literature search for IEK studies reporting $m, n$, and $P_{\mathrm{w}}$ values based on the methodological approach of Fardeau et al. (1991). Only values from topsoil layers (0-30 cm layer, if reported) were compiled. The data set includes all papers cited by Achat et al. (2016) in accordance with our aforementioned selection criteria, plus more recent publications. In addition, data obtained from the published literature were supplemented with unpublished data (seven soils), from studies carried out in the Group of Plant Nutrition (ETH Zurich). This resulted in a final data set of 217 soils taken from 41 references (see Supplement Table S1). The soils represented 19 soil groups across the world reference base (IUSS Working Group WRB, 2015), 26 countries, and all continents except Antarctica. Eighty-five soils were from cropland, 64 from grassland, and 32 from forest, while for 36 soils land use was not specified. Several studies (58 soils) used a simplified version of Eq. (3). Since the simplified version leads to only minor differences in parameter estimation, we assumed that this would not affect calculation of $K_{\mathrm{m}}$ (Fardeau et al., 1991). To avoid overrepresentation, sample sizes of two articles reporting many samples of similar soils were randomly reduced, from 30 to 10 (Compaoré et al., 2003) and from 48 to 12 (Tran et al., 1988).

In addition, we carried out a literature search for IEK studies on long-term $\mathrm{P}$ fertilizer field experiments. We found published data across 18 long-term experiment sites (Oberson et al., 1993, 1999; Fardeau et al., 1991; Gallet et al., 2003; Morel et al., 1994). The soils represented the following soil groups (IUSS Working Group WRB, 2015): Cambisols, Chernozems, Ferralsols, Fluvisols, Gleysols, and Luvisols. In general, the field experiments involved different types of mineral and organic $P$ fertilizers applied at varying rates. The difference in inputs minus outputs led to a range in $\mathrm{P}$ budgets from -52 to $125 \mathrm{~kg} \mathrm{Pha}^{-1} \mathrm{yr}^{-1}$.

\subsection{Data analysis}

Isotopically exchangeable P (i.e., $E$ values: $E_{(t)}$ in $\mathrm{mg} \mathrm{kg}^{-1}$ ), the amount of $\mathrm{P}$ that can reach the soil solution within a given time frame, is calculated using Eq. (4) (Hamon et al., 2002; Fardeau, 1996).

$E_{(t)}=P_{\mathrm{W}} \times \frac{R}{r_{(t)}}$

While IEK experiments only last several minutes, $E_{(t)}$ values can be extrapolated beyond the IEK experiment based on Eqs. (3) and (4) (Frossard et al., 1994; Morel and Plenchette, 1994; Buehler et al., 2003). Extrapolated $E_{(t)}$ values are highly influenced by concentrations of $P_{\mathrm{w}}$. One of the main challenges of the IEK experiment is the accurate and precise determination of $P_{\mathrm{w}}$, particularly in high P-fixing soils (Randriamanantsoa et al., 2013). Analysis involving $E_{(t)}$ could only be performed for studies that reported $P_{\text {inorg }}$ in addition to $P_{\mathrm{w}}, m$, and $n$.

To examine the relationship between $K_{\mathrm{m}}$ and isotopically exchangeable P, $E_{(t)}$ was calculated for $t=0$ to $129600 \mathrm{~min}$ (equal to 3 months) using Eq. (4). First, we calculated the difference between $E_{(1)}$ and $E_{(0)}$ as $\log _{10}\left(E_{(1)}\right)-\log _{10}\left(E_{(0)}\right)$. We then tested if $K_{\mathrm{m}}$ was a significant predictor of this difference using linear regression. To determine the timespan over which $K_{\mathrm{m}}$ affected $E_{(t)}$, we performed linear regression between $K_{\mathrm{m}}$ and $E_{(t)}$ at $t=1$ to $129600 \mathrm{~min}$. We also carried out linear regression with $P_{\mathrm{w}}$ and $P_{\text {inorg }}$ as predictors of $E_{(t)}$ over the aforementioned time points, respectively. During data analysis, we noticed that different $P_{\mathrm{w}}$ levels were differently sensitive to predictor variables. Therefore, we used Jenks natural breaks optimization to systematically partition the $P_{\mathrm{w}}$ data into three clusters using R package "classInt" (Bivand et al., 2015). 
To show sensitivity of $K_{\mathrm{m}}$, we assumed relative standard deviations (standard deviation/mean; \%) of $10 \%$ for each reported $m$ and $n$. Uncertainty was then approximated using the partial derivatives approach for error propagation (Eq. 5; $\mathrm{Ku}, 1966)$. By assuming independent errors of the two fitted parameters, we obtain an upper bound on the error of $K_{\mathrm{m}}$ (Weiss et al., 2006):

$s_{K_{\mathrm{m}}}=\sqrt{\left(\frac{\partial K_{\mathrm{m}}}{\partial m}\right)^{2} s_{m}^{2}+\left(\frac{\partial K_{\mathrm{m}}}{\partial n}\right)^{2} s_{n}^{2}}$.

We used R (R Core Team, 2017) for all statistical analyses and to create the images. All model regressions were checked and the model fit determined using significance of fit $(p=0.05)$ and the regression coefficient $\left(R^{2}\right)$.

\subsection{Analysis of long-term field experiments}

The $\mathrm{P}$ fertilizer budgets were calculated as the average annual input of $\mathrm{P}$ fertilizer minus that of crop offtake $\left(\mathrm{kg} \mathrm{Pha}^{-1} \mathrm{yr}^{-1}\right)$. Each site had three to four P treatments: usually one with a negative budget, one with a balanced budget, and one with a positive budget. To determine the effect of P budget on $P_{\mathrm{w}}$ and $K_{\mathrm{m}}$, we calculated the slope of linear regressions between $\mathrm{P}$ budget and $P_{\mathrm{w}}$. The slope of the line relating $P_{\mathrm{w}}$ to $\mathrm{P}$ budget can be taken as a field PBC, since the slope of $P_{\mathrm{w}}$ corresponds to the change in $P_{\mathrm{w}}$ over the change in soil $\mathrm{P}$ concentration (Eq. 1). Next, we investigated if there was a relationship between the thus-determined PBC and $K_{\mathrm{m}}$.

\section{Results and discussion}

\subsection{Global analysis of $\mathbf{P}$ turnover in the soil solution $\left(K_{\mathbf{m}}\right)$}

The turnover rate of $\mathrm{P}$ in the soil solution ranged 9 orders of magnitude from $10^{-2}$ to $10^{6} \mathrm{~min}^{-1}$ across the 217 soils surveyed (Fig. 1). However, approximately half of the soils had a $\mathrm{P}$ turnover rate within the range of $10^{0}$ to $10^{2} \mathrm{~min}^{-1}$. Clear differences in $K_{\mathrm{m}}$ between different soil groups suggest that $K_{\mathrm{m}}$ is related to soil properties governing kinetics of inorganic $\mathrm{P}$ in the soil solution system. Surface soil horizons of Ferralsols had the highest values of $K_{\mathrm{m}}$, followed by Andosols and Cambisols (Fig. 1). High $K_{\mathrm{m}}$ values of Ferralsols suggest that $\mathrm{P}$ in these soils is rapidly adsorbed, i.e., these soils have a high P-buffering capacity. Three of the four lowest $K_{\mathrm{m}}$ values were found in Podzols, soils which are known to have low P-sorbing capacity (Chen et al., 2003; Achat et al., 2009).

Fardeau, Morel, and Boniface (Fardeau et al., 1991) showed that $K_{\mathrm{m}}$ is largest for small values of $n$ and $m$, and becomes smaller as $n$ approaches 0.5 , and as $m$ approaches 1. Values of $n$ and $m$ have often been found to correlate

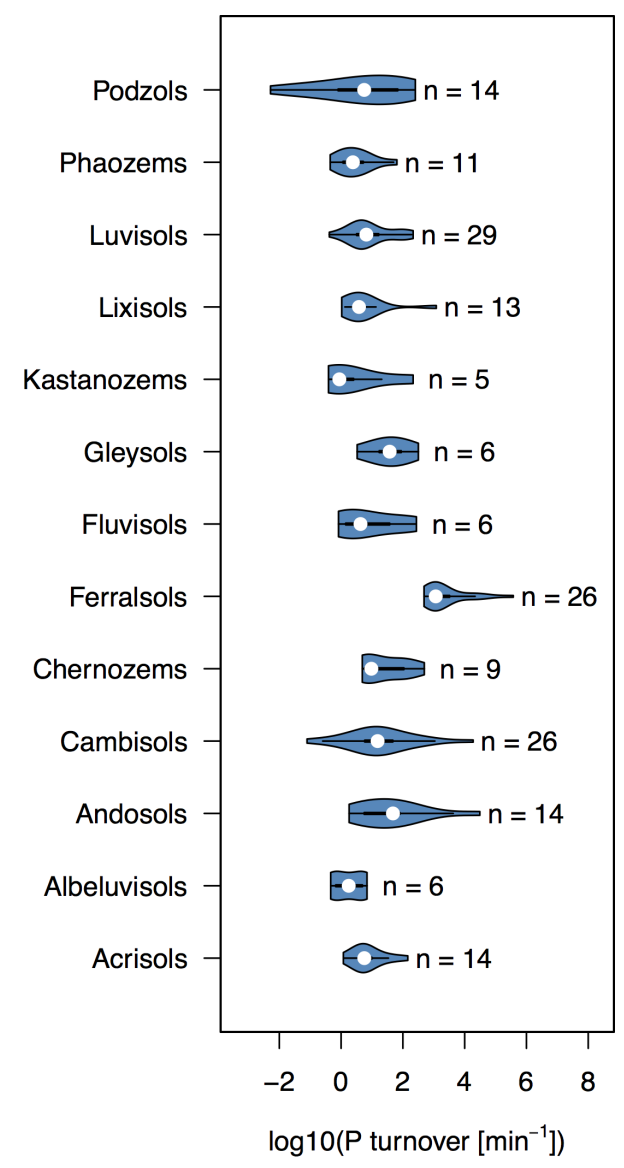

Figure 1. Violin plots of $\mathrm{P}$ turnover $\left(K_{\mathrm{m}}\right)$ for different world reference base soil groups. Only soil groups with at least five observations were plotted. The number of observations in each violin is written next to the plot. Violin plots were made using the $\mathrm{R}$ package "vioplot" (Adler, 2005).

with soil properties $(\mathrm{pH}$, carbonate concentration, oxalateextractable $\mathrm{Al} / \mathrm{Fe}$, organic matter, etc.; Tran et al., 1988; Demaria et al., 2013; Frossard et al., 1993; Achat et al., 2013). A global compilation study showed that low values of $n$ occur for soils with low concentrations of oxalate-extractable $\mathrm{Al}$ and $\mathrm{Fe}$, which are indicative of amorphous $\mathrm{Al}$ and $\mathrm{Fe}$ oxides (Achat et al., 2016). In contrast, low values of $m$ tend to occur for soils with a low ratio of organic $\mathrm{C}$ to $\mathrm{Al}$ and Fe oxides (Achat et al., 2016). The high $K_{\mathrm{m}}$ values of Ferralsols are due to extremely low $m$ values (mean $=0.025$, $\mathrm{SD}=0.012, n=26$ ), and are consistent with low ratios of organic $\mathrm{C}$ to $\mathrm{Al}$ and $\mathrm{Fe}$ oxides typically reported in these soils (Randriamanantsoa et al., 2013). The Podzols in the data set, on the other hand, have distinguishably high $m$ values $($ Mean $=0.50, \mathrm{SD}=0.43, n=14)$, consistent with the low $\mathrm{Al}$ and $\mathrm{Fe}$ oxide content of the upper horizon of Podzols (Achat et al., 2009). However, small sample sizes per soil group and large spans in soil properties even within soil groups mean that group-specific $K_{\mathrm{m}}$ values should not be over-interpreted. 


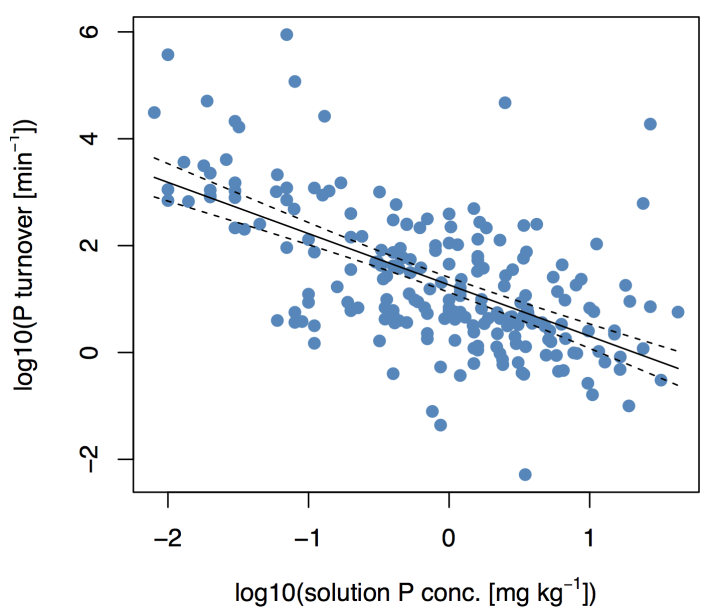

Figure 2. Simple linear regression between soil solution $P$ turnover $\left(K_{\mathrm{m}}\right)$ and soil solution $\mathrm{P}$ concentration $\left(P_{\mathrm{W}}\right)$ for 217 soils. The equation is given by $\log 10\left(K_{\mathrm{m}}\right)=1.26-0.960 \times \log 10\left(P_{w}\right)$ with $F=127, p<10^{-15}$, and $R^{2}=0.37$. Dashed lines represent the $95 \%$ confidence interval.

\subsection{Relationship between soil solution $P$ turnover $\left(K_{m}\right)$ and concentration of soil solution $P\left(P_{w}\right)$}

There was a negative correlation between $K_{\mathrm{m}}$ and $\mathrm{P}_{w}$, as shown in Fig. (2) and described in Eq. (6):

$\log 10\left(K_{\mathrm{m}}\right)=1.26-0.960 \times \log 10\left(P_{\mathrm{w}}\right)$

with $F=127, p<10^{-15}$, and $R^{2}=0.37$. The two variables $P_{\mathrm{w}}$ and $K_{\mathrm{m}}$ are important in governing plant-available $\mathrm{P}$, because the former describes the amount of $\mathrm{P}$ in solution and the latter describes the rate at which it is exchanged. At $t=1 \mathrm{~min}$, the highest values of $E_{(t)}$ occurred for soils with high values of $K_{\mathrm{m}}$ and $P_{\mathrm{w}}$, whereas the lowest values of $E_{(t)}$ occurred for soils with low values of $K_{\mathrm{m}}$ and $P_{\mathrm{w}}$ (Fig. S1 in the Supplement). The relationship was less clear at $t=1$ day (Fig. S1). However, the trend that lowest $E$ values occurred for soils with a low $K_{\mathrm{m}}$ and low $P_{\mathrm{w}}$ is still apparent at $t=1$ day.

The negative correlation between $K_{\mathrm{m}}$ and $\mathrm{P}_{w}$ confirms our second hypothesis, that soils with high $P_{\mathrm{w}}$ would have low $K_{\mathrm{m}}$, and is in accordance with findings from other studies using different methodological approaches. For example, it has been observed that sorption is less pronounced on heavily fertilized soils, due to more negative surface charge (Barrow and Debnath, 2014). In our study, high $K_{\mathrm{m}}$ values imply the presence of many potential binding sites, where $\mathrm{P}$ may adsorb or precipitate. This leads to a rapid exchange between sorption sites and the soil solution, as solution $\mathrm{P}$ quickly binds to a new site. Consequently, $P_{\mathrm{w}}$ is low. On the other hand, slower turnover rates of $P$ in the soil solution and high $P_{\mathrm{w}}$ occur when P-binding sites are few or saturated.

\subsection{Soil solution $P$ turnover $\left(K_{\mathrm{m}}\right)$ as a buffer of isotopically exchangeable $P\left(E_{(t)}\right)$}

We found that $K_{\mathrm{m}}$ is an important buffer of isotopically exchangeable P. As $t$ increases, $E_{(t)}$ values diverge from $P_{\mathrm{w}}$ and eventually approach $P_{\text {inorg. Interestingly, the range of }}$ $E_{(t)}$ values decreased with time (Fig. 3a). While $P_{\mathrm{w}}$ values ranged almost 4 orders of magnitude, $E_{(1)}$ values only ranged 3 orders of magnitude. Furthermore, differences in $E$ values among soils of low, middle, and high $P_{\mathrm{w}}$ decreased with time. We found that the difference between $\log _{10}\left(E_{(1)}\right)$ and $\log _{10}\left(E_{(0)}\right)$ was strongly correlated with $\log 10\left(K_{\mathrm{m}}\right)$ $\left(F=615, p<10^{-15}\right.$, and $\left.R^{2}=0.79\right)$. Thus, soils with fast rates of $K_{\mathrm{m}}$ had large increases in $E_{(t)}$ compared to soils with slow rates of $K_{\mathrm{m}}$, which showed little difference in $E_{(t)}$ from $E_{(0)}$ to $E_{(1)}$. Furthermore, soils with the largest increases in $E_{(t)}$ had low concentrations of $P_{\mathrm{w}}$ but high values of $K_{\mathrm{m}}$ (Fig. 3b).

While it is evident that $E_{(t)}$ and $K_{\mathrm{m}}$ are related since both variables are calculated from the same isotope exchange kinetic parameters, the dependency reveals that many soils with low concentrations of $P_{\mathrm{w}}$ attained $E$ values comparable to other soils due to extremely high soil solution $\mathrm{P}$ turnover rates (Fig. 3b). One can thus interpret that a soil with high $K_{\mathrm{m}}$ has a higher $\mathrm{PBC}$ and that a majority of $\mathrm{P}$ applied as fertilizer will be quickly adsorbed. On the other hand, high turnover means that there is a large flux of $\mathrm{P}$ ions through the soil solution, and phosphate ions in solution are quickly replaced through desorption when plants take up P. If soils with $E_{(1 \mathrm{~min})}$ value of over $5 \mathrm{mg} \mathrm{P} \mathrm{kg}^{-1}$ are considered highly $\mathrm{P}$ fertile (Gallet et al., 2003), high P fertility can be found in both soils with high $P_{\mathrm{w}}$ and/or soils with low $P_{\mathrm{w}}$ but high $K_{\mathrm{m}}$ (Fig. S1). Soils with low $P_{\mathrm{w}}$ and low $K_{\mathrm{m}}$, such as most Lixisols, also have low $E$ values. Thus, $\mathrm{P}$ fixing by soils is reversible and says little about $\mathrm{P}$ availability.

\subsection{Time frame over which $K_{\mathrm{m}}$ buffers isotopically exchangeable $\mathbf{P}\left(E_{(t)}\right)$}

On which time frame is $E_{(t)}$ dependent on $K_{\mathrm{m}}$ ? By performing linear regressions among $P_{\mathrm{w}}, K_{\mathrm{m}}$, and $P_{\text {inorg }}$, respectively, and $E_{(t)}$ for $t=1 \mathrm{~min}$ to 3 months, we found that the fits are strongly dependent on $P_{\mathrm{w}}$ class (high, middle, low). Based on Jenks natural breaks optimization, three clusters of $P_{\mathrm{w}}$ were determined: 0.008-0.16 $(n=46), 0.16-1.9$ $(n=94)$, and $1.9-42.5 \mathrm{mg} \mathrm{kg}^{-1}(n=77)$. Calculating the $R^{2}$ of the regression as a function of time showed that for the class of high- $P_{\mathrm{w}}$ soils, $P_{\mathrm{w}}$ explained $60 \%$ of variability in $E_{(t)}$ at $1 \mathrm{~min}$ (Fig. 4a). However, $P_{\mathrm{w}}$ lost power as a predictor of $E_{(t)}$ rapidly, explaining only $20 \%$ of variability by $t=60$ min. In contrast, soils with low concentrations of $P_{\mathrm{w}}$ showed no relationship between values of $E_{(t)}$ and $P_{\mathrm{w}}$ even at short time spans. Thus, the concentration of $\mathrm{P}$ in the soil solution has a strong legacy on plant $\mathrm{P}$ availability for soils with high $P_{\mathrm{w}}$ at short time spans, but does not indicate $\mathrm{P}$ 
(a)

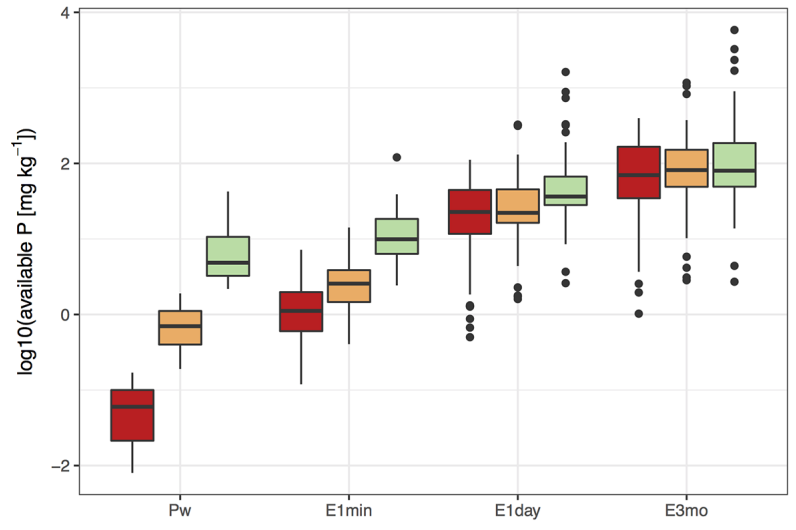

(b)

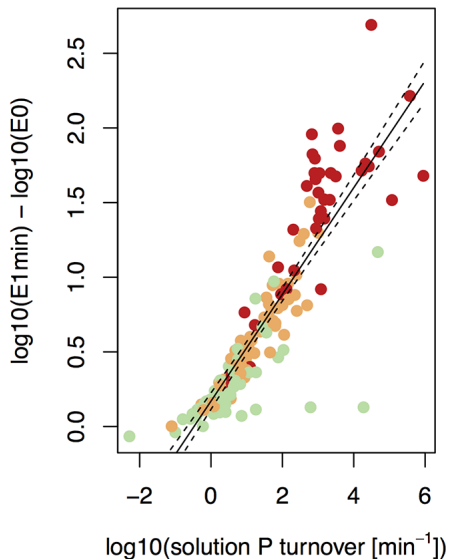

Figure 3. Soil solution $\mathrm{P}$ turnover $\left(K_{\mathrm{m}}\right)$ as a driver of available $\mathrm{P}\left(E_{(t)}\right)$. While there is a large range in $\mathrm{P}$ availability at $t=0\left(P_{\mathrm{W}}\right)$, this variability becomes smaller and gradually uncoupled from $P_{\mathrm{W}}$ class for longer time frames $(t=1,1440,129600$ min a). The growth in $\mathrm{P}$ availability between $t=0$ and $t=1$ is dependent on $K_{\mathrm{m}}(\mathbf{b})$. Simple linear regression between $K_{\mathrm{m}}$ and the difference between $E_{(1)}$ and $E_{(0)}$ is given by $\log 10\left(E_{(1)}\right)-\log 10\left(E_{(0)}\right)=0.170+0.357 \times \log 10\left(K_{\mathrm{m}}\right)$ with $F=615, p<10^{-15}$, and $R^{2}=0.79 . n=170$. Red, orange, and green colors refer to classes of low, middle, and high $P_{\mathrm{W}}$ as determined by Jenks natural breaks optimization. In (b), dashed lines represent the $95 \%$ confidence interval.

(a)

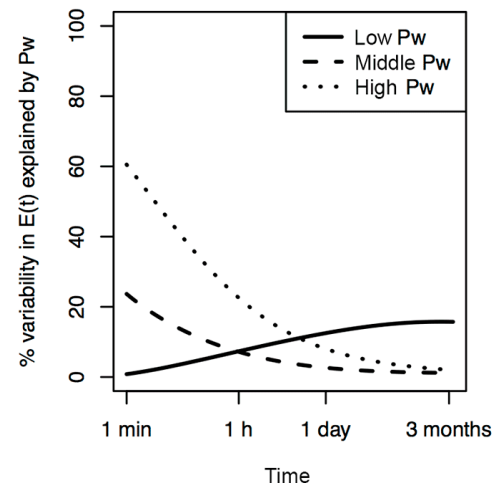

(b)

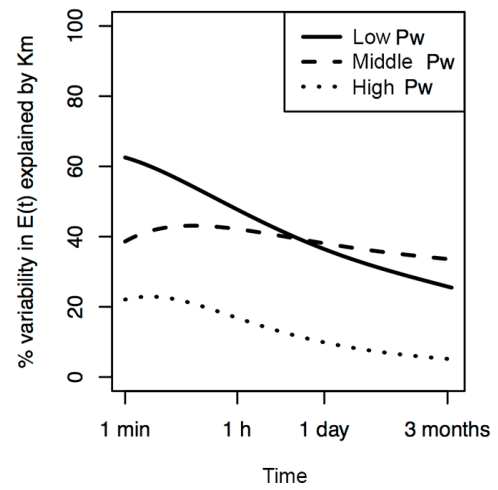

(c)

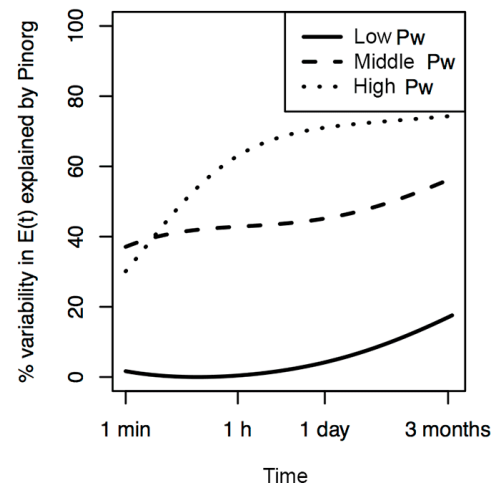

Figure 4. $R^{2}$ of simple linear regressions between isotopically exchangeable $\mathrm{P}\left(E_{(t)}\right)$ explained by predictors $P_{\mathrm{W}}(\mathbf{a}), K_{\mathrm{m}}(\mathbf{b})$, and $P_{\text {inorg }}(\mathbf{c})$ as a function of time. Regressions were fit separately for each class of $P_{\mathrm{W}}$ (low, middle, high), as determined by Jenks natural breaks optimization. Low $P_{\mathrm{W}}=0.008-0.16 \mathrm{mg} \mathrm{kg}^{-1}(n=46)$, middle $P_{\mathrm{W}}=0.16-1.9 \mathrm{mg} \mathrm{kg}^{-1}(n=94)$, and high $P_{\mathrm{W}}=1.9-42.5 \mathrm{mg} \mathrm{kg}-1(n=77)$.

availability in soils with low concentrations of $P_{\mathrm{w}}$. In these soils, values of $E_{(t)}$ are primarily driven by $K_{\mathrm{m}}$ (Fig. 4b). Eventually both $K_{\mathrm{m}}$ and $P_{\mathrm{w}}$ lose predictive power, as $E_{(t)}$ inevitably approaches $P_{\text {inorg }}$ (see Eq. 4; Fig. 4c). However, predictive power of $P_{\text {inorg }}$ is again dependent on $P_{\mathrm{w}}$ class.

$E_{(t)}$ over time spans between 1 min and 3 months were differently related to predictors $P_{\mathrm{w}}, K_{\mathrm{m}}$, and $P_{\text {inorg }}$ depending on concentrations of $P_{\mathrm{w}}$. The effect of $K_{\mathrm{m}}$ on $E_{(t)}$ is thus strongly dependent on $P_{\mathrm{w}}$. In P-depleted soils the kinetic component is crucial in predicting a soil's $\mathrm{P}$ availability. An underestimation of the kinetic components of $\mathrm{P}$ availability will lead to over-fertilization of P-fixing soils. In more P-rich soils, however, $\mathrm{P}$ availability can be relatively accurately as- sessed with static measures, i.e., the concentration of $\mathrm{P}$ in the solution and the total inorganic $\mathrm{P}$ in the soil.

\section{5 $\quad K_{\mathrm{m}}$ buffers fertilizer application in long-term fertilizer experiments}

There was a positive relationship between $P_{\mathrm{w}}$ and $\mathrm{P}$ budget across all 18 long-term $\mathrm{P}$ fertilizer experimental sites, which is consistent with the study of Morel et al. (2000). However, the slopes spanned 3 orders of magnitude, from $0.007\left(\mathrm{mg} \mathrm{P} \mathrm{kg}^{-1} \mathrm{soil}\right) /\left(\mathrm{kg} \mathrm{Pha}^{-1} \mathrm{yr}^{-1}\right.$; Ferralsol, Colombia; Oberson et al., 1999) to 3.9 $\left(\mathrm{mg} \mathrm{Pkg}^{-1}\right.$ soil) $/\left(\mathrm{kg} \mathrm{Pha}^{-1} \mathrm{yr}^{-1}\right.$; Chernozem, Canada; Morel et al., 1994). This shows that soil solution $\mathrm{P}$ is more 


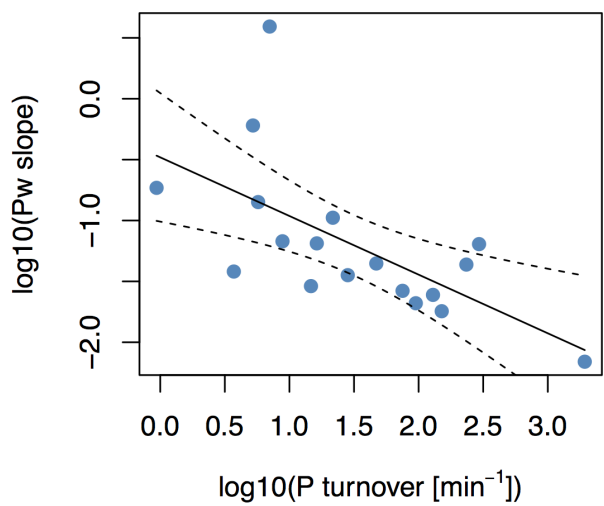

Figure 5. Simple linear regression between phosphorus-buffering capacity $(\mathrm{PBC})$ and soil solution $\mathrm{P}$ turnover $\left(K_{\mathrm{m}}\right)$ for 18 long-term $\mathrm{P}$ fertilizer experiments. $\mathrm{PBC}$ was calculated as the slope of the regression between $P_{\mathrm{W}}$ and $\mathrm{P}$ budget. $\mathrm{PBC}$ was found to correlate with $K_{\mathrm{m}}$, as given by $\log 10(\mathrm{PBC})=-0.481-0.482 \times \log 10\left(K_{\mathrm{m}}\right)$, with $R^{2}$ of $0.40(F=10.8, p=0.0047)$. Dashed lines represent $95 \%$ confidence interval.

strongly buffered in some soils than others. Results from the fertilizer experiments thus confirm that in high P-sorbing soils, such as Ferralsols, additions of $\mathrm{P}$ fertilizers may lead to only incremental increases in solution P concentration (Roy et al., 2016). However, this does not necessarily translate to $\mathrm{P}$ availability (Pypers et al., 2006).

$\mathrm{PBC}$ on the field experiments, taken as the slope of $P_{\mathrm{w}}$ increase with increasing $\mathrm{P}$ budget, was negatively dependent on $K_{\mathrm{m}}\left(F=10.8, p=0.0047\right.$, and $R^{2}=0.40$; Fig. 5). In other words, soils with higher $K_{\mathrm{m}}$ values were characterized by slower increases in $P_{\mathrm{w}}$ at similar yearly $\mathrm{P}$ input-output budgets, and vice versa. Both $\mathrm{PBC}$ and $K_{\mathrm{m}}$ are measures which describe the exchange of $\mathrm{P}$ between the soil solution and solid phases (Olsen and Khasawneh, 1980; Fardeau et al., 1991). However, the two have never been directly related. Data from long-term field experiments enabled us to compare $K_{\mathrm{m}}$ to field-scale PBC. The fact that the two are correlated in fertilizer field experiments thus underlines our findings from the global soil investigation that $K_{\mathrm{m}}$ and PBC provide information on the same underlying processes.

\subsection{Implications for using $K_{\mathrm{m}}$}

Most previous studies involving isotopic exchange kinetics have focused on analyzing $m, n$, and $E$ values (Frossard et al., 1993; Achat et al., 2016; Tran et al., 1988; Brédoire et al., 2016). However, $m$ and $n$ are simply statistical parameters, whereas $K_{\mathrm{m}}$ can be readily interpreted in terms of soil processes (Fardeau et al., 1991). $K_{\mathrm{m}}$ is the mechanism behind $\mathrm{PBC}$ and is useful in explaining $\mathrm{P}$ availability. However, when using $K_{\mathrm{m}}$, it is important to be aware of its limitations (as described in the methods section) and its sensitivity to the parameters $m$ and $n$. (Fig. 6) Depending on the study, a relatively large uncertainty for $K_{\mathrm{m}}$ may be acceptable because

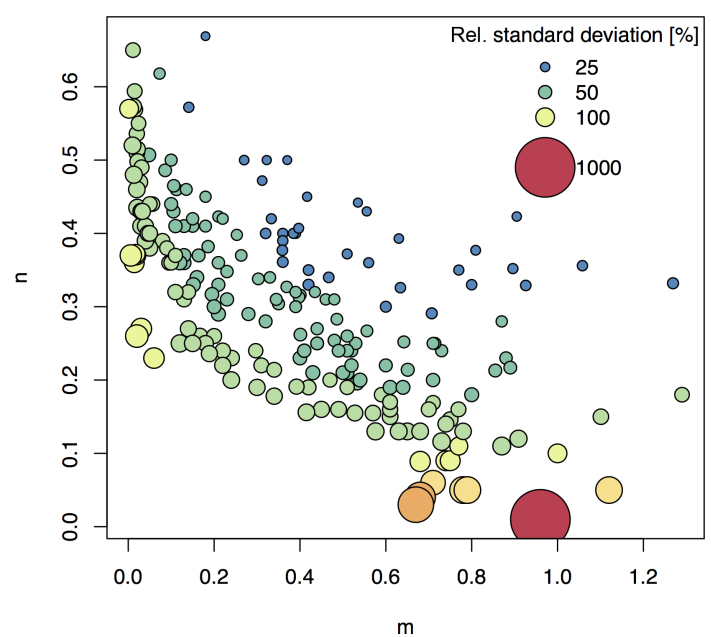

Figure 6. Relative standard deviations (RSDs) of $K_{\mathrm{m}}$ after error propagation assuming $10 \%$ uncertainty in $m$ and $n$ input parameters. The plot shows the $m$ and $n$ values from the 217 soils included in this global compilation study. Uncertainty in $K_{\mathrm{m}}$ was approximated using the partial derivatives approach. Bubble size and color relates to the RSD of $K_{\mathrm{m}}$ for the plotted $m$ and $n$ combination.

differences in $K_{\mathrm{m}}$ between soils or treatments often vary on orders of magnitude (Frossard et al., 2011; Fardeau et al., 1991). However, for low values of $m$ and/or $n, K_{\mathrm{m}}$ calculation becomes very sensitive to uncertainty in $m$ and/or $n$, and relative errors may be much higher than $100 \%$ (Fig. 6). Future studies should take this into account and conduct appropriate error propagation, or consult Fig. 6 to get an overview of sensitive $m$ and $n$ ranges.

While we focused our analysis on P studies, the derivation of $K_{\mathrm{m}}$ as well as the finding that there is extremely rapid exchange between solid and liquid phases is equally relevant for other nutrients and/or pollutants with strongly sorbing ion species. The isotope exchange kinetic approach has also been successfully applied to study availability of $\mathrm{Zn}$ (Sinaj et al., 1999), Cd (Gray et al., 2004; Gérard et al., 2000), Ni (Echevarria et al., 1998), As (Rahman et al., 2017), and U (Clark et al., 2011), and applications are also plausible for other elements with radioisotopes. Isotope exchange kinetic studies with $\mathrm{Zn}, \mathrm{Cd}$, and $\mathrm{Ni}$ have used the same method as studies on $\mathrm{P}$ analyzed here, also modeling the decline in radioactivity using Eq. (3; Gray et al., 2004; Sinaj et al., 1999; Echevarria et al., 1998). For such studies, the derivation of $K_{\mathrm{m}}$ as it is presented here is directly transferable and might provide additional useful information for understanding soilsolution exchange.

\subsection{Environmental implications}

Our study provides new insight into the diffusion-based mechanisms of $\mathrm{P}$ buffering across a large range of soil types. Prior to this study, little was known about soil solution $\mathrm{P}$ turnover rate, as $K_{\mathrm{m}}$ had previously been calculated by only 
a handful of studies. Our analysis of 217 soils showed that $K_{\mathrm{m}}$ is inversely proportional to $P_{\mathrm{w}}$ and is an important determinant of plant-available P. Biological adaptations to $\mathrm{P}$ availability have received a lot of attention, as it has been shown that plant communities have different strategies for $\mathrm{P}$ nutrition depending on P availability (Lambers et al., 2008). Indeed, biological activity acts as an important buffer of $P$ availability in many ecosystems, with higher fluxes of biological $\mathrm{P}$ often occurring when there are lower fluxes of physicochemical P (Bünemann et al., 2016, 2012). Our global compilation of 217 samples demonstrated there is another buffer of soil solution $\mathrm{P}$, which is independent of biological activity and exclusively diffusion-based. Soils with a low concentration of $\mathrm{P}$ in the soil solution tend to have a high $\mathrm{P}$ turnover rate, thus buffering isotopically exchangeable $\mathrm{P}$ values. This does not mean that negative balances of $\mathrm{P}$ will improve the availability of soil $P$ for plant uptake, rather it explains why changes in $\mathrm{P}$ availability are not as large as suggested by more drastic changes in $P_{\mathrm{w}}$.

Our findings complement the notion that there are two categories of soils in regard to $\mathrm{P}$ dynamics. In many low$P_{\mathrm{w}}$ soils, sorption is extremely high and the soil solution is buffered from P inputs or outputs (Barrow and Debnath, 2014). For these soils, the prevalence of sites with fast exchange rates is crucial to assure a steady flux of $\mathrm{P}$ to the soil solution (Fig. 3b). In terms of agricultural management, in such a soil, $\mathrm{P}$ fertilization has to be higher than $\mathrm{P}$ output via crop removal to account for the buffering effect (Roy et al., 2016). However, once a soil reaches a certain $P$ level and binding sites are saturated by phosphate and other anions, $\mathrm{P}$ exchange is less important and fertilizer inputs can be lowered to equal crop offtake (Syers et al., 2008). For these soils, additional $\mathrm{P}$ inputs will be directly reflected by an increase in $\mathrm{P}$ in the soil solution, and $\mathrm{P}$ availability is largely driven by the amount of $\mathrm{P}$ in the soil solution (Fig. 4a). A better understanding of $\mathrm{P}$ kinetics in soil will allow more effective nutrient management to meet the dual goals of improving agricultural production while reducing fertilizer use and pollution.

Data availability. The global soil and fertilizer field experiment data sets used in this study are available in the Supplement.

\section{Information about the Supplement}

The derivation of $K_{\mathrm{m}}$, a table presenting isotope exchange kinetic properties of soils used in the study, and figures relating $E$ values to $P_{\mathrm{w}}$ and $K_{\mathrm{m}}$ are available in the Supplement.

Supplement. The supplement related to this article is available online at: https://doi.org/10.5194/bg-15-105-2018-supplement.
Author contributions. The project was conceived and carried out by JH with support from EF, TM, and JJ. JJ provided the derivation of $K_{\mathrm{m}}$. JH prepared the manuscript with contributions from all coauthors.

Competing interests. The authors declare that they have no conflict of interest.

Acknowledgements. We thank Astrid Oberson for her helpful comments. The project was funded by the Swiss National Science Foundation (project no. 200021_162422), which is gratefully acknowledged.

Edited by: Sönke Zaehle

Reviewed by: two anonymous referees

\section{References}

Achat, D. L., Bakker, M. R., Augusto, L., Saur, E., Dousseron, L., and Morel, C.: Evaluation of the phosphorus status of Pdeficient podzols in temperate pine stands: combining isotopic dilution and extraction methods, Biogeochemistry, 92, 183-200, https://doi.org/10.1007/s10533-008-9283-7, 2009.

Achat, D. L., Bakker, M. R., Augusto, L., Derrien, D., Gallegos, N., Lashchinskiy, N., Milin, S., Nikitich, P., Raudina, T., Rusalimova, O., Zeller, B., and Barsukov, P.: Phosphorus status of soils from contrasting forested ecosystems in southwestern Siberia: effects of microbiological and physicochemical properties, Biogeosciences, 10, 733-752, https://doi.org/10.5194/bg10-733-2013, 2013.

Achat, D. L., Pousse, N., Nicolas, M., Brédoire, F., and Augusto, L.: Soil properties controlling inorganic phosphorus availability: general results from a national forest network and a global compilation of the literature, Biogeochemistry, 127, 255-272, https://doi.org/10.1007/s10533-015-0178-0, 2016.

Adler, D.: vioplot: Violin plot, R Package version 0.2. 2005.

Andersson, K. O., Tighe, M. K., Guppy, C. N., Milham, P. J., McLaren, T. I., Schefe, C. R., and Lombi, E.: XANES Demonstrates the Release of Calcium Phosphates from Alkaline Vertisols to Moderately Acidified Solution, Environ. Sci. Technol., 50, 4229-4237, https://doi.org/10.1021/acs.est.5b04814, 2016.

Barrow, N. J.: A mechanistic model for describing the sorption and desorption of phosphate by soil, J. Soil Sci., 34, 733-750, https://doi.org/10.1111/j.1365-2389.1983.tb01068.x, 1983.

Barrow, N. J. and Debnath, A.: Effect of phosphate status on the sorption and desorption properties of some soils of northern India, Plant Soil, 378, 383-395, https://doi.org/10.1007/s11104014-2042-8, 2014.

Beckett, P. H. T. and White, R. E.: Studies on the phosphate potentials of soils, Plant Soil, 21, 253-282, https://doi.org/10.1007/bf01377744, 1964.

Bivand, R., Ono, H., Dunlap, R., and Stigler, M.: classInt: Choose Univariate Class Intervals, R package version 0.1-24., 2015.

Bolland, M. D. A. and Allen, D. G.: Phosphorus sorption by sandy soils from Western Australia: effect of previously sorbed P on P 
buffer capacity and single-point $\mathrm{P}$ sorption indices, Soil Res., 41, 1369-1388, https://doi.org/10.1071/SR02098, 2003.

Brédoire, F., Bakker, M. R., Augusto, L., Barsukov, P. A., Derrien, D., Nikitich, P., Rusalimova, O., Zeller, B., and Achat, D. L.: What is the P value of Siberian soils? Soil phosphorus status in south-western Siberia and comparison with a global data set, Biogeosciences, 13, 2493-2509, https://doi.org/10.5194/bg-132493-2016, 2016.

Buehler, S., Oberson, A., Sinaj, S., Friesen, D. K., and Frossard, E.: Isotope methods for assessing plant available phosphorus in acid tropical soils, European J. Soil Sci., 54, 605-616, 10.1046/j.1365-2389.2003.00542.x, 2003.

Bünemann, E. K., Oberson, A., Liebisch, F., Keller, F., Annaheim, K. E., Huguenin-Elie, O., and Frossard, E.: Rapid microbial phosphorus immobilization dominates gross phosphorus fluxes in a grassland soil with low inorganic phosphorus availability, Soil Biol. Biochem., 51, 84-95, https://doi.org/10.1016/j.soilbio.2012.04.012, 2012.

Bünemann, E. K., Augstburger, S., and Frossard, E.: Dominance of either physicochemical or biological phosphorus cycling processes in temperate forest soils of contrasting phosphate availability, Soil Biol. Biochem., 101, 85-95, https://doi.org/10.1016/j.soilbio.2016.07.005, 2016.

Burkitt, L. L., Moody, P. W., Gourley, C. J. P., and Hannah, M. C.: A simple phosphorus buffering index for Australian soils, Soil Res., 40, 497-513, https://doi.org/10.1071/SR01050, 2002.

Carpenter, S. R., Caraco, N. F., Correll, D. L., Howarth, R. W., Sharpley, A. N., and Smith, V. H.: Nonpoint pollution of surface waters with phosphorus and nitrogen, Ecol. Appl., 8, 559-568, https://doi.org/10.1890/10510761(1998)008[0559:NPOSWW]2.0.CO;2, 1998.

Chen, C. R., Condron, L. M., Sinaj, S., Davis, M. R., Sherlock, R. R., and Frossard, E.: Effects of plant species on phosphorus availability in a range of grassland soils, Plant Soil, 256, 115130, https://doi.org/10.1023/a:1026273529177, 2003

Clark, M. W., Harrison, J. J., and Payne, T. E.: The pHdependence and reversibility of uranium and thorium binding on a modified bauxite refinery residue using isotopic exchange techniques, J. Colloid Interf. Sci., 356, 699-705, https://doi.org/10.1016/j.jcis.2011.01.068, 2011.

Compaoré, E., Frossard, E., Sinaj, S., Fardeau, J. C., and Morel, J. L.: Influence of land-use management on isotopically exchangeable phosphate in soils from Burkina Faso, Commun. Soil Sci. Plan., 34, 201-223, https://doi.org/10.1081/css-120017426, 2003.

Demaria, P., Flisch, R., Frossard, E., and Sinaj, S.: Exchangeability of phosphate extracted by four chemical methods, J. Plant Nutr. Soil Sc., 168, 89-93, https://doi.org/10.1002/jpln.200421463, 2005.

Demaria, P., Sinaj, S., Flisch, R., and Frossard, E.: Soil properties and phosphorus isotopic exchangeability in cropped temperate soils, Commun. Soil Sci. Plan., 44, 287-300, https://doi.org/10.1080/00103624.2013.741896, 2013.

Echevarria, G., Morel, J. L., Fardeau, J. C., and Leclerc-Cessac, E.: Assessment of Phytoavailability of Nickel in Soils, J. Environ. Qual., 27, 1064-1070, https://doi.org/10.2134/jeq1998.00472425002700050011x, 1998.
Elser, J. and Bennett, E.: Phosphorus cycle: A broken biogeochemical cycle, Nature, 478, 29-31, 2011.

Fardeau, J. C.: Cinètique d'èchange des ions phosphate dans les systèmes sol-solution. Vèrification expèrimentale de l'èquation thèorique, C.R. Acad. Sci. Paris, 300, 371-376, 1985.

Fardeau, J. C.: Le phosphore assimilable des sols : sa représentation par un modèle fonctionnel à plusieurs compartiments, Agronomie, 13, 317-331, 1993.

Fardeau, J. C.: Dynamics of phosphate in soils, An isotopic outlook, Fert. Res., 45, 91-100, https://doi.org/10.1007/bf00790658, 1996.

Fardeau, J.-C., Morel, C., and Boniface, R.: Phosphate ion transfer from soil to soil solution: kinetic parameters, Agronomie, 11, 787-797, 1991.

Frossard, E., Feller, C., Tiessen, H., Stewart, J. W. B., Fardeau, J. C., and Morel, J. L.: Can an isotopic method allow for the determination of the phosphate-fixing capacity of soils?, Commun. Soil Sci. Plan., 24, 367-377, https://doi.org/10.1080/00103629309368807, 1993.

Frossard, E., Morel, J. L., Fardeau, J. C., and Brossard, M.: Soil isotopically exchangeable phosphorus: A comparison between E and L values, Soil Sci. Soc. Am. J., 58, 846-851, https://doi.org/10.2136/sssaj1994.03615995005800030031x, 1994.

Frossard, E., Achat, D. L., Bernasconi, S. M., Fardeau, J.-C., Jansa, J., Morel, C., Randriamanantsoa, L., Sinaj, S., and Oberson, A.: The use of tracers to investigate phosphate cycling in soil-plant systems, edited by: Bünemann, E. K., Springer, Heidelberg, 5991,2011

Gallet, A., Flisch, R., Ryser, J.-P., Frossard, E., and Sinaj, S.: Effect of phosphate fertilization on crop yield and soil phosphorus status, J. Plant Nutr. Soil Sc., 166, 568-578, https://doi.org/10.1002/jpln.200321081, 2003.

Gérard, E., Echevarria, G., Sterckeman, T., and Morel, J. L.: Cadmium Availability to Three Plant Species Varying in Cadmium Accumulation Pattern, J. Environ. Qual., 29, 1117-1123, https://doi.org/10.2134/jeq2000.00472425002900040012x, 2000.

Gérard, F.: Clay minerals, iron/aluminum oxides, and their contribution to phosphate sorption in soils - A myth revisited, Geoderma, 262, 213-226, https://doi.org/10.1016/j.geoderma.2015.08.036, 2016.

Gray, C. W., McLaren, R. G., Günther, D., and Sinaj, S.: An assessment of cadmium availability in cadmium-contaminated soils using isotope exchange kinetics, Soil Sci. Soc. Am. J., 68, 1210 1217, https://doi.org/10.2136/sssaj2004.1210, 2004.

Hamon, R. E., Bertrand, I., and McLaughlin, M. J.: Use and abuse of isotopic exchange data in soil chemistry, Soil Res., 40, 13711381, https://doi.org/10.1071/SR02046, 2002.

Hedley, M. J., White, R. E., and Nye, P. H.: Plant-induced changes in the rhizosphere of rape (Brassica-napus var Emerald) seedlings 3. Changes in $\mathrm{L}$ value, soil phosphate fractions and phosphatase-activity, New Phytol., 91, 45-56, https://doi.org/10.1111/j.1469-8137.1982.tb03291.x, 1982.

IUSS Working Group WRB: World reference base for soil resources 2014, update 2015: International soil classification system for naming soils and creating legends for soil maps, World Soil Resources Reports No. 106. Rome, FAO, 2015. 
$\mathrm{Ku}, \mathrm{H} .:$ Notes on the use of propagation of error formulas, Journal of Research of the National Bureau of Standards. Section C: Engineering and Instrumentation, 70, 263, 1966.

Lambers, H., Raven, J. A., Shaver, G. R., and Smith, S. E.: Plant nutrient-acquisition strategies change with soil age, Trends Ecol. Evol., 23, 95-103, https://doi.org/10.1016/j.tree.2007.10.008, 2008.

Menezes-Blackburn, D., Zhang, H., Stutter, M., Giles, C. D., Darch, T., George, T. S., Shand, C., Lumsdon, D., Blackwell, M., Wearing, C., Cooper, P., Wendler, R., Brown, L., and Haygarth, P. M.: A holistic approach to understanding the desorption of phosphorus in soils, Environ. Sci. Technol., 50, 3371-3381, https://doi.org/10.1021/acs.est.5b05395, 2016.

Morel, C. and Plenchette, C.: Is the isotopically exchangeable phosphate of a loamy soil the plant-available P?, Plant Soil, 158, 287297, https://doi.org/10.1007/bf00009502, 1994.

Morel, C., Tiessen, H., Moir, J. O., and Stewart, J. W. B.: Phosphorus transformations and availability under cropping and fertilization assessed by isotopic exchange, Soil Sci. Soc. Am. J., 58, 1439-1445, https://doi.org/10.2136/sssaj1994.03615995005800050023x, 1994.

Morel, C., Tunney, H., Plénet, D., and Pellerin, S.: Transfer of phosphate ions between soil and solution: Perspectives in soil testing, J. Environ. Qual., 29, 50-59, https://doi.org/10.2134/jeq2000.00472425002900010007x, 2000.

Oberson, A., Fardeau, J. C., Besson, J. M., and Sticher, H.: Soil phosphorus dynamics in cropping systems managed according to conventional and biological agricultural methods, Biol. Fert. Soils, 16, 111-117, https://doi.org/10.1007/bf00369411, 1993.

Oberson, A., Friesen, D. K., Tiessen, H., Morel, C., and Stahel, W.: Phosphorus status and cycling in native savanna and improved pastures on an acid low-P Colombian Oxisol, Nutr. Cycl. Agroecosys., 55, 77-88, https://doi.org/10.1023/a:1009813008445, 1999.

Obersteiner, M., Peñuelas, J., Ciais, P., van der Velde, M., and Janssens, I. A.: The phosphorus trilemma, Nat. Geosci., 6, 897898, https://doi.org/10.1038/ngeo1990, 2013.

Oehl, F., Oberson, A., Sinaj, S., and Frossard, E.: Organic phosphorus mineralization studies using isotopic dilution techniques, Soil Sci. Soc. Am., 65, 780-787, 2001.

Olsen, S. R. and Khasawneh, F. E.: Use and limitations of physicalchemical criteria for assessing the status of phosphorus in soils, in: The Role of Phosphorus in Agriculture, edited by: Khasawneh, F. E., Sample, E. C., and Kamprath, E. J., American Society of Agronomy, Crop Science Society of America, Soil Science Society of America, Madison, WI, 361-410, 1980.

Pierzynski, G. M. and McDowell, R. W.: Chemistry, Cycling, and Potential Movement of Inorganic Phosphorus in Soils, in: Phosphorus: Agriculture and the Environment, edited by: Sims, J. T. and Sharpley, A. N., Agronomy Monograph, 46, American Society of Agronomy, Crop Science Society of America, and Soil Science Society of America, Madison, WI, 53-86, 2005.
Pypers, P., Delrue, J., Diels, J., Smolders, E., and Merckx, R.: Phosphorus intensity determines short-term $\mathrm{P}$ uptake by pigeon pea (Cajanus cajan L.) grown in soils with differing $\mathrm{P}$ buffering capacity, Plant Soil, 284, 217-227, https://doi.org/10.1007/s11104006-0051-y, 2006.

Rahman, M. S., Clark, M. W., Yee, L. H., Comarmond, M. J., Payne, T. E., Kappen, P., and Mokhber-Shahin, L.: Arsenic solid-phase speciation and reversible binding in longterm contaminated soils, Chemosphere, 168, 1324-1336, https://doi.org/10.1016/j.chemosphere.2016.11.130, 2017.

Randriamanantsoa, L., Morel, C., Rabeharisoa, L., Douzet, J. M., Jansa, J., and Frossard, E.: Can the isotopic exchange kinetic method be used in soils with a very low water extractable phosphate content and a high sorbing capacity for phosphate ions?, Geoderma, 200-201, 120-129, https://doi.org/10.1016/j.geoderma.2013.01.019, 2013.

R Core Team: R: A language and environment for statistical computing. R Foundation for Statistical Computing, Vienna, Austria, 2017.

Roy, E. D., Richards, P. D., Martinelli, L. A., Coletta, L. D., Lins, S. R. M., Vazquez, F. F., Willig, E., Spera, S. A., VanWey, L. K., and Porder, S.: The phosphorus cost of agricultural intensification in the tropics, Nat. Plants, 2, 16043, https://doi.org/10.1038/nplants.2016.43, 2016.

Sinaj, S., Mächler, F., and Frossard, E.: Assessment of isotopically exchangeable zinc in polluted and nonpolluted soils, Soil Sci. Soc. Am. J., 63, 1618-1625, https://doi.org/10.2136/sssaj1999.6361618x, 1999.

Syers, J. K., Johnston, A., and Curtin, D.: Efficiency of soil and fertilizer phosphorus use: Reconciling changing concepts of soil phosphorus behaviour with agronomic information, Food and Agriculture Organization of the United Nations, Rome, 2008.

Tilman, D., Cassman, K. G., Matson, P. A., Naylor, R., and Polasky, S.: Agricultural sustainability and intensive production practices, Nature, 418, 671-677, https://doi.org/10.1038/nature01014, 2002.

Tran, T. S., Giroux, M., and Fardeau, J. C.: Effects of soil properties on plant-available phosphorus determined by the isotopic dilution phosphorus32 method, Soil Sci. Soc. Am. J., 52, 1383-1390, https://doi.org/10.2136/sssaj1988.03615995005200050033x, 1988.

Weiss, N. A., Holmes, P. T., and Hardy, M.: A Course in Probability, Pearson Addison Wesley, 2006.

Xiong, L. M., Zhou, Z. G., Fardeau, J. C., Feng, G. L., and $\mathrm{Lu}, \mathrm{R}$. K.: Isotopic assessment of soil phosphorus fertility and evaluation of rock phosphates as phosphorus sources for plants in subtropical China, Nutr. Cycl. Agroecosys., 63, 91-98, https://doi.org/10.1023/a:1020501007558, 2002. 